\title{
The Surgical Management in War of Penetrating Wounds Contaminated with Chemical Warfare Agents
}

\author{
G J Cooper \\ $\mathrm{PhD}$ \\ Senior Adviser/Trauma
}

Chemical and Biological Defence Establishment, Porton Down, Salisbury

Col J M Ryan

MCh, FRCS, Late RAMC

Professor of Military Surgery

Royal Army Medical College, Millbank, London SW1P 4RJ

\author{
Lt Col K A Galbraith \\ FRCS, RAMC \\ Senior Lecturer in Military Surgery
}

Chemical and Biological Defence Establishment, Porton Down, Salisbury

\begin{abstract}
SUMMARY: Military surgeons in a future conflict may face the problem of wounds contaminated with chemicab warfare (CW) agents. No useful guidelines for this eventuality exist - nor any assessment of the specific CW risk $\overline{\mathrm{D}}$ such casualties or to the surgical teams operating on them.

The principal hazard to surgeons is direct contact with contaminated clothing in the wound. Practices ar $\overrightarrow{8}$ recommended to reduce this threat significantly. Thorough wound excision augmented by lavage with a specifie proprietary hypochlorite solution will provide effective wound decontamination without producing unacceptable $\vec{\oplus}$ tissue damage.

The vapour hazard at surgery is very low - respirators are unnecessary but goggles or glasses should be worn prevent conjunctival splashes of potentially contaminated body fluids.
\end{abstract}

\section{Introduction}

With the dissolution of the Warsaw Pact, the apparent chemical warfare $(\mathrm{CW})$ threat to the UK armed forces was greatly reduced. However, Operation Granby served as a reminder that the threat is not extinct - $\mathrm{CW}$ agents are easily produced and remain potentially 'the poor nation's nuclear weapon' - so the Army Medical Services may yet have to deal with $\mathrm{CW}$ casualties in a future conflict.

There is detailed guidance for the medical management of CW casualties in both the classified and open (1) literature. There are also well established surgical guidelines for managing the wounds contaminated with bacteria and debris produced by modern battle (2). Combined injuries however are the Cinderella of military surgery - what little literature there is on this subject addresses medical problems such as the interactions between nerve agents and anaesthetics or relaxants. There are no useful publications about the surgical treatment of wounds contaminated with $\mathrm{CW}$ agents, nor any that clarify the specific chemical risks to such casualties - or themselves - perceived by surgeons.

The aim of this article is to address the potential of wounds contaminated with nerve agents or sulphur mustard $(\mathrm{H})$, to clarify the real and perceived risks to patients and surgeons, and to offer practical management guidelines.

\section{Perceived Risks}

There is certainly a perception of a problem in military surgical circles with regard to the persistence of $\mathrm{CW}$ agents in wounds. Continuing absorption of nerve agent by the casualty, and delayed local and general wound healing and long term effects from systemic absorption of $\mathrm{H}$ are perceived as problems (1). There is also a fear of a contact hazard to surgical teams - surgical gloves are penetrated rapidly by liquid agents - and of a vapour $\mathbb{\mathbb { D }}$ hazard during wound exploration, particularly from $\mathrm{H}$ to $\overline{\bar{F}}$ the surgeon's eyes (the parts of the body most sensitive and vulnerable to $\mathrm{H}$ ). Such fears might lead to attempts to operate wearing respirators or even full individual protective equipment (IPE) even in an operating theatre within collective protection (COLPRO) - with consequent 음 gross degradation of surgical performance. This article $>$ will explain why this is not necessary, and how simple practical procedures will reduce the threat to surgical o teams.

True Risks

In reality, the threat to casualties and surgical teamso 
would depend upon the type, quantity and persistence of $\mathrm{CW}$ agent in the wound. The contamination density of the agent on clothing and the amount of clothing transferred into the wound by the fragment or bullet have been shown to define the quantity of agent. The amount and form of the in-driven cloth and the type of agent then determine the persistence of the agent within the wound. This is also influenced by the type of wound, and the delay between contamination of the wound and wound excision, during which agent may been absorbed systemically, bound, or hydrolysed.

\section{Persistence and Absorbtion of $\mathrm{CW}$ agents in wounds}

Experimental work has shown that $\mathrm{CW}$ agents may be absorbed from wounds very rapidly - even from high energy transfer wounds with severe soft tissue injury with devitalisation (1). Agents can also persist in wounds. The incidence of death, acetylcholinesterase depression and persistence of agent will depend on a large number of factors such as: type of agent (nerve or $\mathrm{H}$ ); simple liquid or thickened form; contamination density on the overgarment; type of missile - bullet or fragment, and its velocity, size, shape and cutting characteristics; energy transfer to the wound (and hence extent of tissue damage); number of wounds; nature of the wounds - small penetrating or large open defect (subsequently contaminated); drug pre-treatment and any post-wounding therapy; delay between injury and primary surgery.

For the purpose of discussion we will divide wounds into those caused by large fragments $(\sim 12 \mathrm{~mm}$ diameter $)$ and small fragments $(\sim 3 \mathrm{~mm}$ diameter).

Large fragment injuries are subdivided into low energytransfer non-perforating wounds (LEn), and high energytransfer (HEn) wounds; the latter may perforate the body, or may remain in the tissues (this makes no effective difference in the $\mathrm{CW}$ context). Small fragments produce principally LEn wounds.

Military jacketed bullets transfer very little material into wounds - the principal source of contaminants is the material sucked in through the exit wound $(3,4)$. For the purposes of this paper, the degree of contamination in bullet wounds can be equated to that of the small antipersonnel fragment.

\section{Influence of type of material contamination}

The size and distribution of material contamination in wounds affects both the persistence of $\mathrm{CW}$ agents and the ability of the surgeon to decontaminate the wound by direct identification and removal of the principal locus of persistence of the agent - discrete pieces of clothing. For both nerve agents and $\mathrm{H}$, the quantity of agent persisting in a wound on clothing is likely to be greater if the material is a discrete, large plug. If the cloth has been shredded by the projectile and deposited as small shreds and fibres, the quantity of persistent agent will probably be very much less, though more will have been absorbed from the fibres scattered in the tissues. Thus, for the purposes of decontamination, cloth pieces may be considered to fall into two groups: "plugged" cloth relatively large intact pieces that a surgeon could probably find within a wound and "shredded" cloth - dispersed shredded fibres that would be difficult to differentiate from soft tissue debris. "Plugged" cloth is likely to be introduced by low energy fragments of large size $(3,4)$ and to result in greater persistence of agent transferred into the wound on NBC suit material. The rate of absorption of a given quantity is likely to be slower than from "shredded" cloth. Consequently, the total dose absorbed is likely to be lower. It should be possible to identify "plugged" cloth in wounds.

"Shredded" cloth is introduced by high energy large fragments, high energy bullets and small fragments. It is dispersed along the wound track and, in high energy transfer wounds, can also be widely dispersed in fascial planes and soft tissues away from the main wound track $(3,4)$. This wider dispersion results in a faster rate of absorption of agent than from "plugged" cloth (even in high energy transfer wounds with presumably reduced tissue perfusion). Thus a greater proportion of the inoculated dose would be absorbed systematically, but consequently there would be a lower persistence of agent within the wound. "Shredded cloth" would be very difficult to identify at surgery, but the consequences of missing it would be less serious.

In practice therefore, fragments of clothing large enough to retain sufficient agent to present a potentias hazard to the surgical team should be large enough to be visible in a wound.

\section{Influence of type of $\mathrm{CW}$ agent on persistence Nerve agent}

Nerve agent - thickened

The higher local contamination densities of these agents on clothing would result in the transfer of greater quantities into the wound. Since the $\mathrm{LD}_{50}$ (absorbed) for a $70 \mathrm{~kg}$ man in $0.5-1 \mathrm{mg}(1)$, most casualties with HEn or multiple LEn wounds through contaminated clothing would probably absorb a lethal dose rapidly and die within minutes. Persistence of agent at surgery would therefore rarely be an issue. With a single small fragment wound, severe acetylcholinesterase depression would be likely with signs of nerve agent poisoning and risk of mortality.

A significant amount of the agent could persist in such a wound but there is unlikely to be a significant vapour hazard.

\section{Nerve agent - unthickened}

With large fragment HEn and LEn wounds, casualties would have significant cholinesterase depression but the majority are likely to survive. Persistence of these agents depends on the type of cloth contamination so with HEn wounds ("shredded" cloth) persistence would be low. Large fragment LEn wounds ("plugged" cloth) would 
retain significant quantities of agent. With a single small fragment wound, only minor acetylcholinesterase depression would be likely with a very low mortality and minimal signs of nerve agent poisoning. No significant quantity of agent would remain in the wound. With multiple small fragments, the combined effects would depend on the number of individual wounds contaminated, a worst case with say 5-10 wounds (all through contaminated clothing) having physiological effects equivalent to those of a large fragment. The overall degree of persistence would still be minimal persistence from multiple wounds each containing a few textile fibres is much less than from one relatively large plug of clothing.

\section{Sulphur Mustard}

Sulphur mustard in missile wounds will not result in acute clinical effects or death and therefore it is quite feasible that surgical teams could be called upon to treat casualties with large quantities of this persistent agent in wounds.

\section{Sulphur mustard - thickened}

Large quantities of agent could remain in wounds (in association not only with cloth but with tissue itself) and present a notable contact hazard. Vapour hazard would probably be low.

\section{Sulphur Mustard - Unthickened}

Small quantities might remain, also presenting a contact hazard. Vapour hazard would be minimal.

With either form of $\mathrm{H}$, large open wounds could also be contaminated subsequently either from contact with contaminated ground or dispersion from the air. $\mathrm{H}$ could also persist in these wounds.

\section{Decontamination}

It can be deduced from the preceding paragraphs that there is a requirement for an external decontaminating solution for safe pre-disposal storage of identifiable cloth fragments removed from contaminated wounds, excised soft tissue and also metallic fragments and other objects such as bone fragments suspected or known to have cloth associated with them. A $10 \%$ solution of sodium or calcium hypochlorite is suitable for this purpose, but is far too cytotoxic for wound decontamination.

As regards internal wound decontamination - a full and radical excision of all damaged and conventionally contaminated tissues, cloth plugs and shredded cloth should also remove all significant $\mathrm{CW}$ agent but in practice this ideal could rarely be achieved with certainty, and even small amounts of thickened nerve agent on missed "shredded" cloth would pose a potential threat to the casualty. Wounds contaminated with thickened $\mathrm{H}$ would need irrigation with a decontaminant to achieve full wound decontamination and thus reduce the perceived and real (minimal) vapour hazard from $\mathrm{H}$-contaminated wounds, and in some cases to reduce the contact hazard to the surgeon.

The standard military decontaminants for materiel are bleach (calcium or sodium hypochlorite) and its moderm derivatives (e.g. alkalnised 5\% sodium dichloro응 isocyanurate); Fullers Earth is used for personnel. Bleach,? and other chlorine-donating compounds, decontaminate by chemically denaturing $\mathrm{CW}$ agents - it achieves this rapidly. The process is aided by an alkaline environment? as is natural hydrolysis to some extent. Strong bleach solutions are too cytotoxic for use in wounds - if used on skin they must be washed off rapidly with soap and water Fullers Earth decontaminates by absorbing CW agentsक Although excellent for overall casualty decontamination $\vec{\circ}$ it is very unsuitable for use in wounds - the finesilicaceous particles would be very difficult to remove్ from the wound even by lavage and retained particles are likely to result in fibrosis (5) and granuloma $(6)$ formation. Much worse in the short term would be the potentiation of local infection - silica particles decrease $\vec{p}$ the phagocytosis and bactericidal activity of bothi macrophages and neutrophils in vitro (7)and in vivo (8) The only suggestion for wound decontamination found in the literature is lavage with isotonic sodium bicarbonate (1). Though logical, this would not produce rappd deactivation of $\mathrm{CW}$ agents, would risk spreading the्p around, would produce a potentially hazardous effluên: and might increase vapour hazard.

We recommend Milton solution, diluted to give 300 parts per million (ppm) available chlorine as an effective decontaminating wound irrigant. Milton solution (Proctior $\&$ Gamble Ltd) is an aqueous solution of sodiumb hypochlorite containing $16.5 \%$ sodium chloride. T strengths are marketed: "Milton Sterilising Fluid" fot̄ hospitals and "Milton" (formerly "Milton 2") for theू home. "Milton Sterilising Fluid" is a 1\% w/v hypochlorite solution with approximately $10,000 \mathrm{ppm}$ available chlorine. This must be diluted to around $3,000 \mathrm{ppm}$ foB wound irrigation. The principal difference between this solution and other chlorine-donating wound irrigants such? as Eusol is its high $\mathrm{pH}$ (around 10-11 at this dilution) This greatly increases its efficacy as a CW agen decontaminant.

Milton does not have a product licence as a wound irrigant - though this would be of little significance where faced in war with a wound contaminated with $\mathrm{CW}$ agent? However, chlorine-donating solutions are now considered to be cytotoxic (9) if applied to wounds for prolonged periods; their used in wound dressings has consequently been banned in many civilian hospitals (10). It is therefore recommended that the solution should always be washedP from the wound with normal saline - it achieves chemica? decontamination in about 2 minutes. "Milton" (formerly "Milton 2") is a $2 \% \mathrm{w} / \mathrm{v}$ hypochlorite solution giving $20,000 \mathrm{ppm}$ available chlorine and is also suitable when appropriately diluted.

"Milton tablets" should not be used as a CW agent్ర 
decontaminant for wounds; the tablets are sodium dichloro-isocyanurate which when dissolved to produce an available chlorine of $3,000 \mathrm{ppm}$, result in a solution of $\mathrm{pH}$ 6-7. This $\mathrm{pH}$ is too low for effective decontamination of $\mathrm{CW}$ agents in wounds.

All other chlorine-donating solutions such as Eusol and Dakin's solution are ineffective as decontaminants. So are conventional wound irrigants such as saline, hydrogen peroxide and Povidone Iodine. Such simple irrigants are actually contraindicated for use in CW agent contaminated wounds - they can disperse agent around the wound, increase the rate of vapour release and thus the potential hazard to the surgical team.

\section{Guidelines for management of wounds contaminated with CW agents}

\section{Assumptions}

The following guidelines for treatment of fragment wounds to limbs contaminated by nerve agent or $\mathrm{H}$ assume that the agent has been carried into the wound on contaminated material or by the subsequent contamination of a gaping wound. They also presume that the casualty has been subjected to standard Casualty Decontamination Centre (CDC) decontamination before entering hospital. In cases of nerve agent poisoning, medical treatment would probably have been started at the CDC or even earlier, and would be continued.

Central to management of all war wounds is adequate wound exploration and excision of tissues deemed to be irrecoverable, with location and removal of foreign material (2). This approach is principally designed to reduce the incidence of wound infection but remains appropriate when wounds are contaminated with $\mathrm{CW}$ agents.

In general, visible cloth within wounds is the principal locus of persisting CW agent and small, widely dispersed fibres retain little or none. However, with thickened $\mathrm{H}$, free agent may be associated with either unidentifiable small fibres of cloth or with the soft tissue itself. This has implications for management.

There are some general assumptions which may assist medical teams in identifying and managing potentially contaminated wounds. These are:

i. Most fragment wounds seen and operated upon at field surgical facilities will be of low energy transfer type with retention of the metallic fragment and transfer of pieces and fibres of NBC suit into the wound - with large fragments, this implies "plugged" cloth.

ii. If a casualty has suffered a penetrating missile wound through clothing contaminated with $\mathrm{CW}$ agent, the agent has been taken into the wound.

iii. Metallic fragments are unlikely to be contaminated unless pieces of cloth are associated with them. The soft tissues and the small unidentifiable cloth fibres which may be presumed to be dispersed within the wound are likely to retain contamination in the presence of thickened $\mathrm{H}$ and to a lesser degree thickened nerve agent, but not in the case of unthickened nerve agent. However, it is good practice to presume contamination in all wounds.

iv. It must be assumed that rigorous exploration and direct cleansing and/or excision of complex wound tracks may be an ideal not fully attainable under field conditions. It may therefore be advisable to irrigate a wound with Milton even if all visible cloth in the debrided wound has been removed.

v. There is no significant vapour release from contaminated wounds covered with dressings. Release of vapour from the entry or exit of discrete penetrating wounds is likely to be insignificant. However, a zero or low reading on a Chemical Agent Monitor (CAM) sampling at an unexplored entry wound does not mean that the depths of the wound are uncontaminated.

vi. The vapour hazard from wounds is not likely to be significant except possible in the case of large open defects severely contaminated with thickened $\mathrm{H}$. There is no significant vapour hazard with nerve agents. The principal risk to the surgeon is probably contact hazard - a contact 'burn' arising from touching $\mathrm{H}$ contaminated cloth, or percutaneous absorption of nerve agent. A discrete plug of cloth covered in blood and tissue debris will release very little vapour, but may retain sufficient agent for a contact hazard.

vii. Thin latex surgical gloves are rapidlyo penetrated by nerve agents and $\mathrm{H}$ even if intact. In any case the risk of loss of glove integrity is high -ing civilian routine operations nearly $50 \%$ of gloves may be holed, often without the surgeons knowledge (11). In war surgery this risk may be increased by bone? splinters and metallic fragments. Such splinters and fragments are also likely to penetrate the operator's fingers.

\section{Practices}

It is prudent to adopt measures to minimise real and perceived risks to patient and surgical team. The following approach is suggested:

i) Wounds should be widely laid open and thoroughly excised - this is any case good military surgical practice (2).

ii) Eye and respiratory protection need not be employed unless a large defect contaminated with thickened $\mathrm{H}$ is suspected - CAM (at eye level) will assist in evaluating this risk. Large cloth fragments should be actively sought in all wounds and removed. CAM may be used to detect areas of persistent contamination after foreign body removal but the lag time of a CAM reading (up to 30 seconds) must be taken into account. Also, since CAM detects vapour, it may not detect a contact hazard within a wound if the release of vapour is impeded by blood clot or soft tissue, especially if the contaminant is deep in a wound. CAM should therefore be checked repeatedly. CAM 
may be alarming - but a bar reading of 5 a few millimeters from a wound may only equate with a reading of $1 \mathrm{a}$ few centimeters above it, and zero at eye level.

iii) In civilian practice it is increasingly considered prudent to wear eye protection to guard against conjunctival splashes of infectious body fluids (12) - it would seem wise to extend this precaution to the debridement of $\mathrm{CW}$ agent contaminated wounds, and indeed to military surgery in general.

iv) During wound exploration and excision, great care should be taken to avoid glove 'holing' and accidental sticking by sharp objects in the wound. Blind finger probing in the depths of a non-debrided wound should be avoided. Wide exposure and excision should precede any digital exploration and, in general, a "no touch" philosophy should be applied. Those who cannot keep their fingers out should either operate in butyl rubber gloves (which may be difficult) or in double surgical gloves, frequently dipped in Milton.

v) Cloth fragments or plugs should not be unravelled in the wound. They should be carefully removed with forceps and placed in the $10 \%$ bleach solution. This solution must not be used for internal wound irrigation - it must be kept separate to obviate this risk. All excised tissue debris should also be considered contaminated, particularly if thickened $\mathrm{H}$ is suspected, and similarly disposed of, as should any retrieved metallic fragments.

vi) If full exploration is carried out, large cloth plugs and fragments will generally be obvious and little difficuly should be encountered in their disposal. Problems will arise under certain conditions such as complex wounds and multiple wounds where full exposure and wound excision may not be possible. Adverse field conditions added to fatigue and inexperience also may result in less than ideal exploration and excision, potentially leaving agent in wounds on undiscovered cloth. Such wounds should certainly be irrigated with Milton, as should those contaminated with large quantities of thickened $\mathrm{H}$, where agent could persist in the wound despite the removal of large cloth fragments and plugs. Thickened agents may be associated with unidentifiable fibres of cloth, soft tissue or both and might not be immediately obvious to the surgeon. CAM would reveal their presence and Milton irrigation be an appropriate and effective response, as it would be for any otherwise unexpected residual contamination revealed by CAM. The default position should be: if in doubt, irrigate.

vii) Wounds irrigated with Milton must be subsequently washed with saline. Irrigation is in any case sound military surgical practice. The effluent does not pose a chemical threat.

viii) It is recommended that the Milton $3000 \mathrm{ppm}$ be made up daily and not stored for long periods at this dilution. ix) Field dressings removed from contaminate wounds may be contaminated on the surface applied to the wound. They should be placed either in a seale container for disposal, or preferably submerged in the $10 \%$ bleach solution. Instruments that have come into contact with contaminated cloth or tissue withis wounds should be placed in this solution for 2 to minutes prior to normal cleaning and sterilisation. It very unlikely that reusable or disposable theatre line $\bar{P}$ would be significantly contaminated, and norma disposal methods should suffice. CAM could be used to verify this.

\section{Caveat - Use of Milton in body cavities}

Milton at a dilution of $3000 \mathrm{ppm}$ is hypertonic, and has a pH of 11.4 It should not be used for irrigation of the् abdomen, since peritoneal irritation may occur leading to the formation of adhesions (13). The cost/benefit balanc of its use in the abdomen harbours a considerable potential long-term adhesion problem resulting front widespread, inappropriate use. In war, all penetratin $\$$ abdominal wounds are likely be managed by fu\& laparotomy to treat faecal contamination an $\phi$ haemorrhage. Wounds caused by large fragment associated with large pieces of chemically contaminate cloth will be uncommon. Standard laparotomy techniqकes are designed to remove all contaminants and should effective in removing any locus of remaining agent wi ihio the peritoneum. In theory a vapour hazard might arise $\frac{0}{4} \mathrm{~d}$ chemically inert irrigant such as saline dislodged a pieccö of clothing lying unsuspected between loops of bowel, \$ut we cannot recommend an irrigant solution that effectively decontaminate residual agent here an $\bar{\Phi}$ ie surgically acceptable. Saline, hydrogen peroxide or mixture of these solutions may continue to be used to perform peritoneal lavage for faecal contamination but th $\overline{8}$ use of these solutions must not be assumed to have decontaminated cloth fragments contaminated with CVP agent. These irrigants may however serve to dislodge material for recovery by aspiration with a large bore sucker - which will rapidly remove any chemical hazard The irrigant solution should not be swabbed out manuall using large abdominal packs as this could increase the vapour hazard. CAM should be used to warn of an hazard but the risk to patients and medical attendant would be small since it is unlikely that significan quantities of available $\mathrm{CW}$ agent would be encountere during laparotomies. Safe practice however suggests that. any non-hypochlorite irrigant solution used to deal with generalised faecal contamination should be considere potentially unsafe and following aspiration by sucke? should be neutralised and disposed of in the externat deontaminant solution of $10 \%$ bleach.

The great majority of wounds to the chest amone surviving casualties would be caused by relatively smail penetrating missiles. Over $80 \%$ of such wounds would be managed by surgery only to the soft tissues of the chese

(1) 
wall and by tube drainage of the pleural cavity. The likelihood of significant chemical contamination of the pleural cavity would be very low. Although adhesion formation in the pleural cavity is less problematical than in the abdomen, the use of Milton here is also not recommended.

Milton should not be used to irrigate eye or brain wounds.

\section{Future Developments}

Promising new research directions include pre-loading with synthesised cholinesterase to scavenge nerve agent, monoclonal antibodies and agent-deactivating enzymes $(14,15)$. Such new biotechnological measures have already been shown to protect animals from multiple lethal doses of nerve agents - and with complete freedom from toxic symptons. This would be a distinct improvement on the current Nerve Agent Pretreatment Set (NAPS). Such compounds may have an important place in the treatment of $\mathrm{CW}$ contaminated wounds, potentially permitting wound decontamination without the cytotoxic effects of hypochlorites. They might also allow casualties with larger amounts of nerve agent sequestered on cloth in wounds to survive to reach surgery, by protecting such casualties from the effects of absorbed agent. However these and other approaches are likely to remain research tools rather than have military applications in the near future.

\section{Conclusions}

The concept of wounds contaminated with $\mathrm{CW}$ agents is an alarming one for surgeons. However, the key to all successful military surgery is planning, preparation and training. Even in a CW environment a surgeon is unlikely to see many such casualties, and by employing these guidelines, should be able to keep the hazards in perspective and take steps to avoid them.

\section{Acknowledgements}

We would like to thank Mr D O H Messent and the staff of Medical Division of the Chemical and Biological Defence Establishment, Porton Down.

(C) British Crown Copyright 1994/MOD

Published with the permission of the Controller of Her Britannic Majesty's Stationery Office.

\section{REFERENCES}

1. NATO Handbook on the medical aspects of NBC defensive operations. Part III - Chemical (Nato Unclassified).
2. Kirby N G, Blackburn G. Field Surgery Pocket Book. London: HMSO 1981.

3. COOPER G J, RYAN J M. Interaction of penetrating missiles with tissues: some common misapprehensions and implications for wound management. $\mathrm{Br} \mathrm{J}$ Surg 1990; 77: 606-610.

4. Ryan J M, CoOper G J, Haywood I R, Milner S M. Field Surgery on a future conventional battlefield: strategy and wound management. Ann R Coll Surg Engl 1991; 73: 13-20.

5. Mowry R G, Sams W M JR, Caulfield J B. Cutaneous silica granuloma. A rare entity or rarely diagnosed? Report of two cases with review of the literature. Arch Dermatol 1991; 127 (5): 692-4.

6. Maeda H, Ford J, Williams M G JR, Dodson R F. An ultrastructural study of acute and long term lung response to commercial diatomaceous earth. J Comp Pathol 1986; 96 (3): 307-17.

7. Zimmerman B T, Canono B P, Campbell P A. Silica decreases phagocytosis and bactericidal activity of both macrophages and neutrophils in vitro. Immunology 1986; 59 (4): 521-5.

8. Gill N J, Bhusnurmath S R, Virk K J, Ganguly N K, Dilwari J B, MahaJan R C. Effect of silica treata ment on histopathology of intestinal and hepati amoebiasis in murine model. Indian J Med Res 1989 89: 426-34.

9. BRENNAN S S, LEAPER D J. The effect of antiseptic 8 on the healing wound: a study using the rabbit eaf chamber. Br J Surg 1985; 72: 780-82.

10. LEAPER D J. EUSOL (editorial). Br Med J 1992; 304: 930-31.

11. GREEN S E, GOMPERTZ R H K. Glove perforation during surgery: What are the risks? Ann $R$ Coll Surg Engl 1992; 74: 306-8.

12. BeLL K M, ClEMENT D A. Eye protection for the surgeon. J R Coll Surg Edinb 1991; 36 (3): 178-9.

13. McDonald G O, Gines S M, Cole W H. Wound irrigation in cancer surgery. AMA Arch Surg 1960; 80: $920-7$

14. DunN M A, Sidell F R. Progress in Medical Defense Against Nerve Agents. JAMA 1989; 262 (5): 649-52

15. Munro N B, Watson A P, Ambrose K R, Griffin G D. Treating Exposure to Chemical Warfare Agents: Implications for Health Care Providers and Community Emergency Planning. Environ Health Perspect 1990; 89: 205-15. 